\title{
The Implementation of the Principles of Lifelong Learning as the Basis of Quality Specialize Education
}

\author{
Oleksandr V. Broiakovskyi ${ }^{1}$, Vita V. Ilchuk ${ }^{2}$, Nataliia M. Mas ${ }^{3}$, Oleksandr S. Kapinus ${ }^{4}$ \& Anastasiia V. Okaievych ${ }^{4}$ \\ ${ }^{1}$ Department of Olympic and Professional Sport Theory and Methodology, Faculty of Physical Education, \\ Volodymyr Vynnychenko Central Ukrainian State Pedagogical University, Kropivnitsky, Ukraine \\ ${ }^{2}$ Department of Methodology of Philological Disciplines and Stylistics of the Ukrainian Language, Faculty of \\ Philology and Journalism named after Michael Stelmakh, Vinnytsia Mykhailo Kotsiubynskyi State Pedagogical \\ University, Vinnytsia, Ukraine \\ ${ }^{3}$ Department of Military Psychology and Pedagogy, Military Faculty of Humanities and Linguistics, Military \\ Institute of Kyiv National Taras Shevchenko University, Kyiv, Ukraine \\ ${ }^{4}$ Department of Moral and Psychological Support of Troops, Institute of Moral and Psychological support, Hetman \\ Petro Sahaidachnyi National Army Academy, Lviv, Ukraine
}

Correspondence: Oleksandr V. Broiakovskyi, Volodymyr Vynnychenko Central Ukrainian State Pedagogical University, 1 Shevchenko str., Kropivnitsky, 25006, Ukraine.

Received: June 10, 2020

doi:10.5430/ijhe.v9n7p12
Accepted: August 3, 2020

Online Published: August 4, 2020

\begin{abstract}
The article reflects the relevant factors of introducing specialized education. The first group of factors relates to the specifics of adolescent development. The second group of factors relates to the development of a network of educational institutions in the education system of modern Ukraine. Small towns and rural areas suffer from scarcity of gymnasiums, lyceums, schools with in-depth study of subjects. At the same time, major million cities also feel the need to increase their numbers. The third group of factors is determined by pan-European educational development objectives. The main attributes of lifelong learning that determine the transformations of specialized education are: formal, substantive and meaningful attributes. Let's briefly consider each of these attributes. A formal attribute implies a temporary duration of the educational process and can be extended to the period of adult life ("lifelong learning"). A substantative attribute orients each pupil to the gradual enrichment of their creative potential. $A$ meaningful attribute reflects the integrity of the lifelong learning cycle.
\end{abstract}

The study of the effectiveness of the implementation of principles of lifelong learning as a basis for specialized education was based on a number of features. First of all, we are talking about the selected sample. After all, to trace the reasonability of applying the principles of continuing education in the process of professional formation it is necessary to diagnose individuals who have passed all the steps of this process. At the same time, the selected population of respondents was divided by gender into two groups. This made it possible to establish the diversity of views of men and women on the problem of continuing education.

The purpose of this study is to provide a comprehensive review of the scientific literature on the specifics of the implementation of the lifelong learning principles and to determine whether professionals feel the need for additional training.

Keywords: pupils, students, lifelong learning, specialized education, continuing education, future specialists, professional mobility

\section{Introduction}

Specialized education is currently, on the one hand, one of the mechanisms for modernizing Ukrainian education, expanding its variability, ensuring accessibility for children from different segments of the population (Suprun, 2013), and, on the other hand, a natural result of the development of the processes of differentiation and individualization of education, a kind of response to the challenges of time, to the changes that are taking place in the world's open educational space (Suprun, 2014). 
This point to the fact that at the present stage of society's development, the speed of change in the science and technology of creating or producing something far outstrips the dynamics of changing generations of specialists in a particular professional field. The task of maintaining the required level of human readiness to perform professional and social functions determines the transition to continuing education, that is, lifelong learning.

However, continuing education is impossible without differentiation and individualization of learning through the construction of individual specialized education programs for each pupil (Bendahmane, El Falaki \& Benattou, 2019; Webster \& Whitworth, 2019).

The implementation of such personal development strategies requires the development of new curricula to organize the educational process (Safana \& Nat, 2019). This process is of particular importance today, with the introduction of a new state educational standard. One of the effective ways of taking individual characteristics of pupils into account is the implementation of pre-specialized and specialized education in the upper grades of secondary schools. As the modern world is characterized by a rapid increase in the volumes of information, a constant expansion of the spheres of human activity and, as a consequence, the need for improvement in a particular highly specialized field, the professional self-determination of a person should begin at the level of secondary school. Specialized differentiation of pupils is aimed at solving this problem.

In these conditions, specialized education should be aimed at implementing a person-centered educational process (Tolochko \& Lymar, 2016). At the same time the possibilities of building individual educational trajectory for pupils are greatly expanded. The transition to specialized education has a number of goals, including:

- provide in-depth study of individual subjects of the program of complete general secondary education;

- create conditions for significant differentiation of the content of education of senior pupils with wide and flexible possibilities of building individual educational programmes by senior pupils;

- promote equal access to full-fledged education for different categories of pupils according to their individual abilities, capacities and needs;

- expand opportunities for socialization of pupils, ensure continuity between general and professional education, more effectively prepare school graduates for professional education programmes in higher educational institutions.

The basic idea behind updating the content of general secondary education is that education should become more individualized, functional and effective.

The theoretical basis of specialized education is psychological and pedagogical research in the field of differentiation and individualization of education. At the same time, the necessity of introducing specialized education is due to a number of factors. In particular, these are factors related to the development of a network of educational institutions in the education system of modern Ukraine. Small towns and rural areas suffer from scarcity of gymnasiums, lyceums, schools with in-depth study of subjects. At the same time, large million cities also feel the need to increase their numbers (Suprun, 2013). Most parents who care about their children's education seek to send their child to a school of high learning outcomes (Lypova, 2007).

However, the transformation of a comprehensive school into the so-called "high-status" is a rather complicated process. Being educated in a gymnasium, lyceum or school with in-depth study of the subject is associated with considerable loads and sometimes overloads for children. Not all children are ready for them since the $1^{\text {st }}$ form. But many pupils aged under $15-16$, that is, up to $9^{\text {th }}-10^{\text {th }}$ form, have an approximate idea of their further educational route. It has already been noted that according to sociological research, more than $70 \%$ of today's senior pupils aged under 15 know what subjects they would like to study more thoroughly. At about the same age, most senior pupils are already determined in their choice of future profession. More than $90 \%$ of pupils go to the senior school, intending to continue their education in higher education institutions (HEIs).

Pre-specialized and specialized preparation of pupils should be based on the continuity of the content of secondary education levels. In elementary school, the main thing is to develop an interest in professional activity, a positive attitude to work, an awareness of the significance of professional activity and its social importance. In secondary school, the pupils of the $5^{\text {th }}-8^{\text {th }}$ forms get acquainted with the professions and the world of work, professional orientation of an individual, the formation of adequate self-assessment of their own abilities and inclinations, the formation of professional self-awareness. At the level of pre-specialized and specialized education in the $9^{\text {th }}-10^{\text {th }}$ and $11^{\text {th }}-12^{\text {th }}$ forms they determine the professional preferences and intentions.

Therefore, it is reasonable to carry out career guidance in the following areas: professional information, professional agitation, professional diagnostics, professional consultations. Professional diagnostics and professional 
counsultations are the main work of the psychological service. Appropriate diagnostic techniques are used in accordance with age periodization and the goals of career guidance. In elementary school, diagnostics of a spectrum of professionally coloured fantasies of a child, diagnostics of the one set of interests to professions, diagnostics of the motivational sphere by means of drawing techniques, questioning are applied.

Secondary schools should work on pupils' personal and professional self-determination. Individual cards are used to monitor the process of making-up a personality, where the career guidance section plays an important role. It traces the dynamics of interests and inclinations of a pupil, obtained with the help of the following methods: differential-diagnostic questionnaire of Klimov, Map of Interests method, survey. At this stage, the key role is assigned to the professional consultations of students, which ensures the development of professional self-awareness and its component - professional self-concept (self-concept as a subject of professional activity). This is facilitated not only by individual professional consultations, but also by mass forms of work: training sessions, electives.

This gradation of pre-specialized education finds its continuity in specialized education. In the conditions of rapid informatization and knowledge development, a specialist in any field should be prepared for a regular self-education. Therefore, we believe that the principles of lifelong learning are fundamental in the implementation of the concept of specialized education. Let's take a closer look at the content of the category "lifelong learning", which is now synonymous with the term "continuing education".

Lifelong learning is a concept that has no conventional definition in the pedagogical literature to date (Annan-Diab \& Molinari, 2017; Fernandes, 2015; Fornell \& Larcker, 1981; Giamellaro, 2014; Josephsen, 2015; Maravilhas, 2015). This concept reflects the idea of changing educational practice in order to increase its social effectiveness for successful life in modern society. In philosophy, continuity is interpreted as the unity, interconnectivity and interdependence of elements that make up a particular system (Dyiak \& Tushko, 2018; Faure et al., 1972; Frontex, 2007; Knowles, Holton III \& Swanson, 2005; Stavitsky, 2013).

In the encyclopedic literature, the continuity of education is formally interpreted "as the endlessness of educational activity, its continuation after the completion of the so-called basic level of education... Continuing professional education is a constant creative renewal, development and improvement of every person throughout life" (Kremin, 2008). This thesis traces the reasonability of orientation of specialized education at school for further positive development of future specialists.

The third group of factors is determined by pan-European education development objectives. The main features of continuing education that determine the transformation of specialized education are formal, substantive and meaningful attributes. Let's look briefly at each of these features.

The formal feature implies a temporary duration of the educational process and can be extended to the period of adult life (continuing education, lifelong learning). The pan-European trend of "lifelong learning" is accepted in developed economies. As our country has also taken this path, we must analysed and use the experience of market economies must. Such key ideas of the lifelong learning principle as basic skills for all, more investment in human resources, the value of education, rethinking approaches to the education of the younger generation are also relevant to the system of specialized education.

A substantative attribute orients each pupil to a gradual enrichment of their creative potential. Theoretical approaches, the accumulated domestic and foreign experience allow putting forward objective requirements for systems of general and professional training of future specialists in the aspect of personal development, adequate to the existing socio-economic situation and which is becoming a part of the culture in modern society.

As a continuation of general education, professional education becomes the educational vector in the construction of the personality of a student with creative activity who has prognostic orientation; is a research process in its essence.

In the light of the above, we note that specialized education system is entering a new stage of its functioning, as there is a transition from preparing a specialist to the formation and development of human personality. Becoming a modern specialist is inseparably linked with his development as an integrated, humane, many-sided personality. Improving the social status of a specialist in a particular professional field requires revision and appropriate adjustment of the system of his training. It seems to be guided by the principles of self-regulation, interaction and development of pedagogical structures that support innovation and progressive tendencies. A meaningful aspect reflects the integrity of the lifelong learning cycle. The strategy of implementation of specialized education involves identification of levels of subjects: general and specialized.

Therefore, we assume that a successful transition to the organization of a specialized education in Ukraine must be accompanied by a lifelong learning process. Continuing education is a fundamental principle of the educational system 
and participation of a person in it throughout the continuous process of his educational activities (Zamora-Polo \& Sánchez-Martín, 2019). The criterion of the concept of "success" of a modern educational institution is the ability to flexibly respond to changing conditions, the ability to train a specialist with the skills to switch to different activities, develop new professionally significant knowledge and skills in connection with possible changes in labour market requirements.

\section{Materials and Methods}

The study of the effectiveness of implementation of lifelong learning principles as a basis for specialized education was based on a number of features. First of all, we are talking about the selected sample. Thus, an adult population was selected to study the existing system of specialized education. After all, to trace the reasonability of applying the principles of continuing education in the process of professional formation, it is necessary to diagnose individuals who have "passed" all the steps of this process. At the same time, the selected population of respondents was divided by gender into two groups. This allowed establishing separation of views of men and women on the problem of continuing education. A special questionnaire was developed to achieve the objectives of this research, reflecting the key points of the problem of organization of specialized education and revealing the attitude of the respondents to the problem (for greater details of the content of the questionnaire see Appendix A).

Methods of mathematical statistics were used to prove the data reliability (Kyveryalg, 1980).

\section{Results and Discussion}

Based on the review of the scientific literature, we conclude that the content of specialized education in Ukraine is developing in three organizational directions: vocational technical education, higher education. The concept of specialized education is being realized through the use of various forms of implementation of the principles of lifelong education (Hertzog, Kramer, Wilson \& Lindenberger, 2008). Today, it is possible to distinguish 2 models of the organization of specialized education relying on the topic of continuing education: the model within the school specialization and the model of the network organization (King, 2009). Based on these models, general educational institution can be either one-field (with only one selected specialization) or multi-field (with multiple specializations) (Lukianova, 2015).

The issue of continuing education can be divided into two main areas. The first is related to the construction of a system of continuing education as part of social practice (socio-educational aspect of continuing education), the second - to the process of assimilation of new life, social, professional experience. That is why, the combination of the principle of continuity of education with the principle of lifelong learning and the formation of a knowledge-based society was proclaimed in the field of adult education in the second half of the 90 's of the $20^{\text {th }}$ century. Thus, an attempt was made to consolidate in the public consciousness an understanding of the mutual responsibility of society, the state and the individual for the development of educational processes.

The European Commission has expanded different training courses within a single Lifelong Learning Program. This program examined the change in the professional and distance learning program that existed until 2006.

The European Employment Strategy agreed on 22 July 2003 proposed guidance on the principles for the development of the training course. These EU Open World Guidelines note the labour shortage and encourage to implement lifelong learning strategies to meet the current requirements of the economy.

Different European institutions focus on lifelong learning. In particular, they regularly conduct statistical surveys. In 2017, the number of people aged between 25 and 64 years reported different forms of middle-aged education, amounting to $9.7 \%$ within the EU. The value is $1.2 \%$ higher than in 2013 . The mean for women is $10.6 \%$, the mean for men is lower $-8.8 \%$. The highest levels of the population with different forms of training are recorded in Sweden, Denmark, Great Britain and Finland - 23\% to 32\%. The lowest levels are in Bulgaria and Romania - 2\% (Table 1). 
Table 1. Quantitative indicators of people involved in various forms of middle age education in 2013 and 2017

\begin{tabular}{|c|c|c|c|c|c|c|c|}
\hline & \multirow[t]{2}{*}{ Countries } & \multicolumn{2}{|l|}{ Total } & \multicolumn{2}{|l|}{ Men } & \multicolumn{2}{|c|}{ Women } \\
\hline & & 2013 & 2017 & 2013 & 2017 & 2013 & 2017 \\
\hline 1 & Belgium & 8.5 & 9.7 & 7.9 & 8.8 & 9.1 & 10.6 \\
\hline 2 & Bulgaria & 6.5 & 8.4 & 6.4 & 8.0 & 6.6 & 8.8 \\
\hline 3 & Czech Republic & 5.1 & 5.7 & 4.8 & 5.5 & 5.4 & 5.9 \\
\hline 4 & Denmark & 24.2 & 29.2 & 21.0 & 24.2 & 27.4 & 34.2 \\
\hline 5 & Germany & 6.0 & 7.8 & 6.4 & 8.0 & 5.6 & 7.6 \\
\hline 6 & Estonia & 6.7 & 7.0 & 5.0 & 4.6 & 8.2 & 9.3 \\
\hline 7 & Ireland & 5.9 & 7.6 & 5.1 & 6.2 & 6.8 & 9.0 \\
\hline 8 & Greece & 2.6 & 2.1 & 2.6 & 2.2 & 2.7 & 2.1 \\
\hline 9 & Spain & 4.7 & 10.4 & 4.3 & 9.3 & 5.1 & 11.5 \\
\hline 10 & France & 7.1 & 7.4 & 7.0 & 7.0 & 7.2 & 7.9 \\
\hline 11 & Italy & 4.5 & 6.2 & 4.2 & 5.9 & 4.8 & 6.6 \\
\hline 12 & Cyprus & 7.9 & 8.4 & 7.1 & 8.1 & 8.5 & 8.6 \\
\hline 13 & Latvia & 7.8 & 7.1 & 5.4 & 4.6 & 10.0 & 9.3 \\
\hline 14 & Lithuania & 3.8 & 5.3 & 2.8 & 3.6 & 4.7 & 6.8 \\
\hline 15 & Luxembourg & 6.5 & 7.0 & 6.8 & 6.5 & 6.1 & 7.4 \\
\hline 16 & Hungary & 4.5 & 3.6 & 4.0 & 3.0 & 4.9 & 4.1 \\
\hline 17 & Malta & 4.2 & 6.0 & 4.7 & 6.4 & 3.6 & 5.7 \\
\hline 18 & Netherlands & 16.4 & 16.6 & 16.1 & 16.1 & 16.8 & 17.0 \\
\hline 19 & Austria & 8.6 & 12.8 & 8.6 & 11.6 & 8.6 & 14.0 \\
\hline 20 & Poland & 4.4 & 5.1 & 3.9 & 4.7 & 4.9 & 5.5 \\
\hline 21 & Portugal & 3.2 & 4.4 & 3.0 & 4.4 & 3.4 & 4.5 \\
\hline 22 & Romania & 1.1 & 1.3 & 1.1 & 1.2 & 1.2 & 1.4 \\
\hline 23 & Slovenia & 13.3 & 14.8 & 12.0 & 13.5 & 14.7 & 16.1 \\
\hline 24 & Slovakia & 3.7 & 3.9 & 3.5 & 3.4 & 3.9 & 4.3 \\
\hline 25 & Finland & 22.4 & 23.4 & 18.6 & 19.4 & 26.2 & 27.5 \\
\hline 26 & Sweden & 31.8 & 32.0 & 28.4 & 26.0 & 35.4 & 38.3 \\
\hline 27 & United Kingdom & 27.2 & 26.6 & 22.7 & 22.0 & 30.9 & 31.2 \\
\hline 28 & Croatia & 1.8 & 2.9 & 1.8 & 3.1 & 1.9 & 2.8 \\
\hline 29 & Turkey & 1.2 & 1.5 & 1.7 & 1.8 & 0.7 & 1.2 \\
\hline 30 & Iceland & 29.5 & 27.9 & 25.0 & 22.4 & 34.1 & 33.7 \\
\hline 31 & Norway & 17.1 & 18.0 & 16.2 & 17.1 & 18.0 & 18.9 \\
\hline 32 & Switzerland & 24.7 & 22.5 & 25.3 & 21.7 & 24.0 & 23.4 \\
\hline
\end{tabular}

The values for companies delivering training reached $21 \%$ in Greece, $90 \%$ in the UK, and $60 \%$ on average in the EU. Positive dynamics is observed in the non-EU countries. Professional training in the developing companies in Germany, the United Kingdom, Austria, Denmark, the Netherlands, Italy and France accounts for about $50 \%$ of companies, while it is no more than $10 \%$ in the EU as a whole.

In a transition to the information society, a fundamentally new knowledge-based system relying on the use of new educational technologies is required (Anderson \& Cuesta-Medina, 2019). Additional requirements are imposed on the system of continuing specialized education, in particular, ensuring its variability. In this case, variability is seen as the ability to provide a wide variety of full-fledged, high-quality and attractive educational trajectories, suited to the needs 
of pupils, which ultimately aims at individualizing education and the demand for future specialists in the labour market (Tække \& Paulsen, 2017).

Continuing specialized education can be considered as a hierarchical system of interconnected subsystems (secondary school, college, technical school, high school, advanced training institutes, postgraduate studies, etc.). Each subsystem of education provides for the formation of professionally competent specialists, ready for professional activity; at the same time, such a system as a whole gives the opportunity to obtain professional education at a higher level. In these conditions, continuity gives the opportunity for educational maneuver, that is, when moving on the levels of professional education, a person determines the duration of training and mastery of several specialties, thus creating his individual educational trajectory (London \& Sessa, 2006; Elkind, 1995).

The outlined requirements for continuous specialized education provide for its flexibility and affordability. The system of specialized continuing education must be designed in such a way that everyone can join the system at any time of professional activity with the least time and effort. That is, it is about providing individual trajectories of the specialized lifelong learning.

The introduction of the term "professional educational trajectory" is largely due to the significant spread of non-standard employment and new forms of flexible use of labour, which led to the formation of a qualitatively new model, which provides for a long process of alternating or parallel circulation and the resumption of training and work (Sezer \& Yilmaz, 2019).

The educational and professional trajectories of young people are closely interrelated and show dependence on the conditions of the environment, the most important of which are the peciliarities of the labour market and the system of education. An educational trajectory, defined as the acquisition by a subject of formal qualifications, institutionally validated competences, acquired experience in the form of knowledge and skills, can be a kind of "investment", and the professional trajectory becomes a social field for the use of these resources or their conversion into the relevant position in the labour market.

According to sociological research, the accumulation of educational capital largerly depends on the starting educational resource - namely, the type of educational institution that boys and girls graduate from. Different training, features of the social characteristics of young people, which is a contingent of the educational institution, produce differentiation in the prevailing value systems, as well as differences in strategies and real behaviour of young people in the future in the fields of education and work. It is known that not every specialist resorts to continuous updating of professional knowledge, skills and abilities. The conducted researches (Vaskivska, 2017) confirm the well-known sociological fact - "education is the fate of the educated", that is, the higher the quality of education, the greater the educational needs and the more often people go to study, invest in education, including continuing education. That is, the focus on specialized self-education needs to be formed while studying at secondary schools.

Unlike individual curricula, the use of lifelong learning principles innovative educational trajectories not only for the individual student/pupil, but also for the group. The specifics of this trajectory are in filling the educational process with practice, that is, the organization of a large proportion of the educational process on the basis of vocational schools, lyceums, higher educational institutions, enterprises, etc.

Another promising direction of using the continuing education principles in specialized education is not only targeted training of specialists for particular companies, but also specialists who are able to establish a new company on their own. It is the creation of "new employers". In the implementation of this direction, it is worth noting the significant role of business incubators, which allow pupils/students to develop entrepreneurial competencies (Lypova, 2007).

Working in a changing environment, a specialist must be constantly ready for possible changes, i.e. to have professional mobility. This quality manifests itself in the creative nature of the activity, in the active search for innovative approaches and technologies, personal initiative and professional communication. At the same time, appealing to the principles of lifelong learning in specialized education promotes pupils'/students' ability to adapt, respond quickly to changes in the labour market, etc.

The concept of "mobility" has been studied by both foreign and domestic researchers. From a sociological perspective, professional mobility is viewed in two ways: as a change in position due to external circumstances, such as changes in the labour market, when mobility is dictated by the need to adapt to real life situations; and as an inner self-improvement of the individual based on stable values and the need for self-improvement. The problem of formation of professional mobility and professional self-awareness of a future specialist should be solved when pupils/students acquire their profession. At the same time, this process involves the orientation of specialized 
education towards the orientation of pupils/students towards the independent updating of knowledge, skills, abilities for comfortable existence in the information society. Nowadays, a significant number of specialists in different specialties see the need to ensure a continuous process of professional development based on self-study.

The logic of empirical verification and statistical conclusions to compare the subjective perceptions of men and women about continuing specialized education is as follows. The answers to the questions presented in the nominal or ordinal scale were processed using the chi-square test. The task of matching the distributions of uniformity in the subsamples of men and women was solved separately. Empirical frequency distributions in men and women were then compared on the basis of the conjunction tables and the chi-square test (Kyveryalg, 1980).

Some questions in the questionnaire can be considered as metric scales. For them, a check was carried out in contrast to the normal distribution using the single-choice criterion - the Kolmogorov-Smirnov criterion, and this criterion was also used to compare the data obtained (Kyveryalg, 1980).

The $\mathrm{Q}$ designation was used in the statistical program to mark variables. In the data, where it is necessary for understanding and does not complicate perception, the complete questions of the questionnaire are provided (ordinal numbers of questions of questionnaire and Q designations do not correspond to each other, since some questionnaire data were drawn up in the statistical Table 2 their names and not under numbers, such as gender). In other cases, Q marks remained. Where necessary for meaningful conclusions, there were also frequency tables with response distribution. The parameters of descriptive statistics were calculated for preliminary analysis of the distribution on the time perspective scales.

Table 2. Descriptive statistics parameters for time perspective metrics $(n=207)$

\begin{tabular}{llllll}
\hline & $\begin{array}{l}\text { Negative } \\
\text { past }\end{array}$ & $\begin{array}{l}\text { Hedonistic } \\
\text { present }\end{array}$ & Future & Positive past & Fatalistic present \\
\hline Mean & 2.679 & 3.3765 & 3.6294 & 3.7626 & $\mathbf{2 . 5 8 7 0}$ \\
Median & 2.640 & 3.4100 & 3.6200 & 3.7800 & $\mathbf{2 . 5 6 0 0}$ \\
Mode & 3.1 & 3.53 & 3.69 & 4.11 & $\mathbf{3 . 0 0}$ \\
Variance & 0.610 & 0.327 & 0.359 & 0.350 & $\mathbf{0 . 4 5 6}$ \\
Asymmetry & 0.226 & -0.342 & -0.289 & -0.425 & $\mathbf{- 0 . 0 1 4}$ \\
St. asymmetry & 0.169 & 0.169 & 0.169 & 0.169 & $\mathbf{0 . 1 6 9}$ \\
error & & & & & \\
Kurtosis & -0.504 & -0.345 & 0.175 & 0.641 & $\mathbf{- 0 . 2 2 0}$ \\
St. excess error & 0.337 & 0.337 & 0.337 & 0.337 & $\mathbf{0 . 3 3 7}$ \\
Span & 3.6 & 2.82 & 3.15 & 3.79 & $\mathbf{3 . 3 3}$ \\
Minimum & 1.0 & 1.71 & 1.85 & 1.77 & $\mathbf{1 . 0 0}$ \\
Maximum & 4.6 & 4.53 & 5.00 & 5.56 & $\mathbf{4 . 3 3}$ \\
\hline
\end{tabular}

Based on the asymmetry and kurtosis figures, as well as the representation of frequency distributions on each scale, a preliminary conclusion was made about the normality of the distribution. Table 1 discusses the respondents' perceptions and memories of their experience of realization as specialists in their business. The data obtained allowed concluding that the implementation of lifelong learning principles into specialized training of future specialists is reasonable.

This is confirmed by the statistics of the respondents' responses as to the desire to continue specialized education. The data obtained are displayed in Tables 3-5.

Table 3. Do you plan to get an education of a higher level? (men, $\mathrm{n}=90$ )

\begin{tabular}{llll}
\hline & Real $\mathbf{N}$ & Expected $\mathbf{N}$ & Remainder \\
\hline 1-yes & 42 & 18.0 & $\mathbf{2 4 . 0}$ \\
$\mathbf{2}-$ most likely yes & 15 & 18.0 & $\mathbf{- 3 . 0}$ \\
$\mathbf{3}-$ difficult to answer & 15 & 18.0 & $\mathbf{- 3 . 0}$ \\
$\mathbf{4}-$ most likely not & 7 & 18.0 & $\mathbf{- 1 1 . 0}$ \\
$\mathbf{5}$ - no & 11 & 18.0 & $\mathbf{- 7 . 0}$ \\
Total & 90 & & \\
\hline
\end{tabular}


Table 4. Q4 - 5. Do you plan to get an education of a higher level? (women, $n=116$ )

\begin{tabular}{llll}
\hline & Real N & Expected N & Remainder \\
\hline 1- yes & 38 & 23.2 & $\mathbf{1 4 . 8}$ \\
2- most likely yes & 33 & 23.2 & $\mathbf{9 . 8}$ \\
3 - difficult to answer & 21 & 23.2 & $\mathbf{- 2 . 2}$ \\
$\mathbf{4}-$ most likely not & 18 & 23.2 & $\mathbf{- 5 . 2}$ \\
$\mathbf{5}$ - no & 6 & 23.2 & $\mathbf{- 1 7 . 2}$ \\
Total & 116 & & \\
\hline
\end{tabular}

Table 5. Criterion statistics

\begin{tabular}{ll}
\hline & Q4 \\
\hline Chi-square & 27.707 \\
Degree of freedom & 4 \\
Asymp. value & .000
\end{tabular}

The resulting numerical values allowed making a number of conclusions. In particular, it is a fact that a large proportion of the men surveyed express the conscious need to increase the level of their specialized education. Such a result exceeded twice our research assumptions about the relevance of continuing education for the adult male population. The above points, however, to the need to improve the system of specialized education of future specialists at the professional training stage.

Thus, based on the chi-square statistics, we see that, in both men and women, the distribution of intentions to obtain higher education differs from the uniform one, based on the observed $\mathrm{N}$ for each response we can conclude that the answers "yes" and "most likely yes" are predominant in both sub-samples. The data obtained indicate that the adult working population of our country needs additional specialized education. Therefore, the assumption of the relevance of the organization of specialized education of pupils/students with the emphasis on continuing education and the orientation of student youth to lifelong learning is confirmed.

Tables 6-8 provide data to confirm the reliability of our study. The methods of mathematical statistics were used for this purpose. The research is based on the scientifically proven findings of contemporary researchers who conducted their studies in the field of innovation and structuring of adult education (Anderson \& Cuesta-Medina, 2019; Sezer \& Yilmaz, 2019; Zamora-Polo \& Sánchez-Martín, 2019).

Table 6 . Coherence tables of observation processing summary

\begin{tabular}{lllllll}
\hline & \multicolumn{1}{l}{ Observation } & Missing & Total \\
\cline { 2 - 7 } & Valid & \multicolumn{5}{l}{} \\
\hline & $\mathrm{N}$ & Persentage & $\mathrm{N}$ & Persentage & $\mathrm{N}$ & Persentage \\
Gender Q4 & 206 & $99.5 \%$ & 1 & $.5 \%$ & 207 & $\mathbf{1 0 0 . 0 \%}$ \\
\hline
\end{tabular}

Table 7. Gender coherence tables

\begin{tabular}{llllllll}
\hline & & Q4 & & & & & \multirow{2}{*}{ Total } \\
\cline { 3 - 6 } & & 1 & 2 & 3 & 4 & 5 & \\
\hline \multirow{2}{*}{ Gender } & Men & 42 & 15 & 15 & 7 & 11 & $\mathbf{9 0}$ \\
& Women & 38 & 33 & 21 & 18 & 6 & $\mathbf{1 1 6}$ \\
\multirow{2}{*}{ Total } & 80 & 48 & 36 & 25 & 17 & $\mathbf{2 0 6}$ \\
\hline
\end{tabular}


Table 8. Chi-square criteria

\begin{tabular}{|c|c|c|c|}
\hline & Value & $\begin{array}{l}\text { Degree of } \\
\text { freedom }\end{array}$ & Asymp. value \\
\hline Pearson's chi-square & 11.157 & 4 & .025 \\
\hline Likelihood ratio & 11.335 & 4 & .023 \\
\hline Linear-by-linear association & .275 & 1 & .600 \\
\hline Number of valid observations & 206 & & \\
\hline
\end{tabular}

Thus, the differences in the empirical distributions for the $5^{\text {th }}$ question of the questionnaire in men and women are statistically significant. We can say that women have a gradual decrease in response rates from full confidence to refusal to receive education of a higher level, while absolute confidence in plans dominate among men, and other frequencies are more even.

\section{Conclusions}

Specialization is a major institutional transformation for the system of general education. It not only meets the requirements of the state, but also reflects private interests of society and individuals. Features of specialized education in the current educational situation are the appeal to adherence to the principles of lifelong education, which is reflected in the following trends: the focus on the development of the subjective position of pupils through the creation of a situation of choice and building individual educational route, orientation to the formation of positive motivation for continuing education throughout life, taking into account the needs of the labour market and geo-economic space of the region. The novelty of specialized education in adherence to the principles of lifelong learning is also that the specialized school is considered only as one of the institutional forms of its implementation, suggesting a network interaction between educational institutions.

The empirical and statistical data obtained confirm the relevance of the application of lifelong learning principles in the organization of quality specialized education. Such activity should be multilevel and cover all structural educational organizations of Ukraine: comprehensive schools, lyceums, vocational education institutions, higher educational institutions. It will provide realization of possibility of continuous professional training of future specialists and will promote their mobility, flexibility to changing conditions of the labour market.

\subsection{Prospects for Further Research}

Further research can be the continuation of improvement of the methodology of specialized education in the institutions of secondary, special and higher education of Ukraine on the principles of continuing education.

\section{References}

Anderson, C. E., \& Cuesta-Medina, L. (2019). Beliefs and practices concerning academic writing among postgraduate language-teacher trainees. Ikala, 24(1), 29-49. http://doi.org/10.17533/udea.ikala.v24n01a01

Annan-Diab, F., \& Molinari, C. (2017). Interdisciplinarity: Practical approach to advancing education for sustainability and for the Sustainable Development Goals. The International Journal of Management Education, 15(2), 73-83. http://doi.org/10.1016/j.ijme.2017.03.006

Bendahmane, M., El Falaki, B., \& Benattou, M. (2019). Toward a personalized learning path through a services-oriented approach. International Journal of Emerging Technologies in Learning, 14(15), 52-66. https://doi.org/10.3991/ijet.v14i15.10951

Dyiak, V., \& Tushko, K. (2018). Educational system in the conditions of today (synergetic interpretation). In Proceedings of the IX international research practice conference: Modern Approaches to Highly Efficient Use of Vehicles, 58-59. Ismail, Ukraine: DI OMA.

Elkind, D. (1995). School and family in the postmodern world. The Phi Delta Kappan, 77(1), 8-14.

Faure, E., Herrera, F., Kaddoura, A.-R., Lopes, H., Petrovsky, A. V., Rahnema, M., \& Ward, F. C. (1972). Learning to be: the world of education today and tomorrow. Paris, France: UNESCO.

Fernandes, P. (2015). Curricular contextualization: Tracking the meanings of a concept. The Asia-Pacific Education Researcher, 22(4), 417-425. https://doi.org/10.1007/s40299-012-0041-1 
Fornell, C. \& Larcker, D. F. (1981). Evaluating structural equation models with unobservable variables and measurement error. Journal of Marketing Research, 18(1), 39-50. https://doi.org/10.1177/002224378101800104

Frontex. (2007). Common core curriculum EU border guard basic training. Warsaw, Poland: Frontex Agency.

Giamellaro, M. (2014). Primary contextualization of science learning through immersion in content-rich settings. International Journal of Science Education, 36(17), 2848-2871. https://doi.org/10.1080/09500693.2014.937787

Hertzog, C., Kramer, A. F., Wilson, R. S., \& Lindenberger, U. (2008). Enrichment effects on adult cognitive development: Can the functional capacity of older adults be preserved and enhanced? Psychological Science in the Public Interest, 9(1), 1-65. https://doi.org/10.1111/j.1539-6053.2009.01034.x

Josephsen, J. (2015). Cognitive load theory and nursing simulation: An integrative review. Clinical Simulation in Nursing, 11, 259-267. https://doi.org/10.1016/j.ecns.2015.02.004

King, P. (2009). The handbook of the evolving research of transformative learning based on the learning activities survey (10th ed.). Charlotte, NC: Information Age Publishing.

Knowles, M. S., Holton III, E. F., \& Swanson, R. A. (2005). The adult learner: the definitive classic in adult education and human resource development (6th ed.). Boston, MA: Elsevier. https://doi.org/10.4324/9780080481913

Kremin, V. G. (Ed.), (2008). Encyclopedia of Education. Kyiv, Ukraine: Yurinkom Inter.

Kyveryalg, A. A. (1980). Research methods in professional pedagogy. Tallinn, USSR: Valgus.

London, M., \& Sessa, V. I. (2006). Continuous learning in organizations: A living systems analysis of individual, group, and organization learning. In F. J. Yammarino \& F. Dansereau (Eds.), Research in multi-level issues: Vol. 5. Multi-level issues in social systems, 123-172. Oxford, UK: Elsevier. https://doi.org/10.1016/S1475-9144(06)05006-5

Lukianova, L. (2015). Continuous lifelong learning: historical overview, current realities. Scientific Bulletin of Melitopol State Pedagogical University. Series: Pedagogy, 2(15), 187-192.

Lypova, L. A. (Ed.), (2007). Profile Education: Theory and Practice. Kyiv, Ukraine: Compass GDP.

Maravilhas, S. (2015). Challenges for education in the information society. In M. Khosrow-Pour (Ed.), Encyclopedia of Information Science and Technology (3rd ed.). Hershey, PA: IGI Global.

Safana, A. I., \& Nat, M. (2019). Students' perception of a blended learning approach in an African higher institution. Journal of Universal Computer Science, 25(5), 515-540.

Sezer, B., \& Yilmaz, R. (2019). Learning management system acceptance scale (LMSAS): A validity and reliability study. Australasian Journal of Educational Technology, 35(3), 15-30. https://doi.org/10.14742/ajet.3959

Stavitsky, O. N. (2013). The priority directions of professional education of a specialist' personality in the process of studies and educational work in a higher education institution. Nauka i studia, 33(101), 3-17.

Suprun, V. (2013). Analysis of the system of vocational education and training in Ukraine in the framework of the “Torino Process”. Kyiv, Ukraine: ETF, MESYSU.

Suprun, V. V. (2014). The concept of development of vocational education of Ukraine in the conditions of decentralization of management (approved by the Board of the Ukrainian Association of District and Regional Councils). Kyiv, Ukraine: MES of Ukraine.

Tække, J. \& Paulsen, M. (2017). Digitalisation of education - the theory of the three waves. Aarhus, Denmark: The Centre for Internet Research.

Tolochko, S., \& Lymar, V. (2016). Innovation aspects of the postindustrial society. Trends in education, 9(1), $253-258$. https://doi.org/10.5507/tvv.2016.037

Vaskivska, H. (2017). Didactic aspects of upper secondary and university education fundamentalization. Science and Education, 5, 46-50. https://doi.org/10.24195/2414-4665-2017-5-9

Webster, L., \& Whitworth, A. (2019). Power and resistance in informed learning. Advances in Librarianship, 46, 115-131. https://doi.org/10.1108/S0065-283020190000046010

Zamora-Polo, F., \& Sánchez-Martín, J. (2019). Teaching for a better world. sustainability and sustainable development goals in the construction of a change-maker university. Sustainability, 11(15), Article 4224. https://doi.org/10.3390/su11154224 


\section{Appendix A}

\section{QUESTIONNAIRE}

Instruction: We ask you to answer the questions of this questionnaire, which aims at revealing your judgments about specialized professional education. Carefully read each question and choose the answer option that most fully and accurately reflects your opinion.

1. Specify your age (full years), gender (male/female)

2. Your position and total duration of service.

3. Specify your professional education level at the moment. Circle the letter of the relevant answer.

a) general secondary education;

b) vocational training;

c) secondary vocational training;

d) higher professional education.

4. If you are currently studying, specify the level of education. Circle the letter of the relevant answer.

a) general secondary education;

b) vocational training;

c) secondary vocational training;

d) higher professional education.

5. Do you plan to get education of a higher level? Circle the letter of the relevant answer and answer the question why.

a) yes;

b) most likely yes;

c) difficult to answer;

d) most likely not;

e) no

Why?

6. If you were to receive professional education again, would you choose the institution where you study or studied? Circle the letter of the relevant answer and answer the question why.
a) yes;
b) most likely yes;
c) difficult to answer;
d) most likely not;
e) no

Why?

7. Do you have a need for changing your professional activity? Circle the letter of the relevant answer and answer the question why.
a) yes;
b) most likely yes;
c) difficult to answer;
d) most likely not;
e) no

Why?

8. Do you need additional professional training or retraining? Circle the letter of the relevant answer and answer the question why.

a) yes; 

b) most likely yes;
c) difficult to answer;
d) most likely not;
e) no

Why?

10. In your opinion, how and how often shall a person receive a professional education throughout life? Circle the letter of the relevant answer or add your own option.
a) getting a professional education once in life is enough;
b) several times, increasing one's level of education from primary to higher;
c) several times, when changing profession;
d) constantly, for the purpose of self-development;
e) constantly, with the advanced training.
e) Your option

11. Assess the role of professional education in employment. Check the appropriate box.

\begin{tabular}{|c|c|c|c|}
\hline & $\begin{array}{l}\text { Plays } \\
\text { role }\end{array}$ & 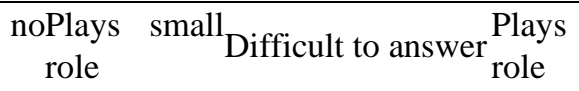 & $\begin{array}{c}\text { significantPlays extremely } \\
\text { important role }\end{array}$ \\
\hline $\begin{array}{l}\text { Primary } \\
\text { education }\end{array}$ & vocational & & \\
\hline $\begin{array}{l}\text { Secondary } \\
\text { education }\end{array}$ & vocational & & \\
\hline $\begin{array}{l}\text { Higher } \\
\text { education }\end{array}$ & professional & & \\
\hline
\end{tabular}

